Article

\title{
Diffusion Bonding of Al-Fe Enhanced by Gallium
}

\author{
Asmawi Ismail ${ }^{1,2}$, Warda Bahanan ${ }^{3}$, Patthi Bin Hussain ${ }^{1, *}$, Asmalina Mohamed Saat ${ }^{2}$ \\ and Nagoor Basha Shaik ${ }^{1}$ (D) \\ 1 Mechanical Engineering Department, Universiti Teknologi PETRONAS, Seri Iskandar 32610, Malaysia; \\ asmawiis@unikl.edu.my (A.I.); nagoor_16000473@utp.edu.my (N.B.S.) \\ 2 Institute of Marine Engineering Technology, Universiti Kuala Lumpur Malaysian, Lumut 32200, Malaysia; \\ asmalina@unikl.edu.my \\ 3 Faculty of Engineering, Universitas Teknologi Sumbawa, Moyo Hulu 84371, Indonesia; \\ wardabahanan96@gmail.com \\ * Correspondence: patthi_hussain@utp.edu.my; Tel.: +60-194704616
}

Received: 3 June 2020; Accepted: 9 July 2020; Published: 12 July 2020

\begin{abstract}
In this research, diffusion bonding was carried out to produce transition joints between mild steel A36 (Fe A36) and aluminium Al 5083 (AA5083) with the presence of gallium (Ga) as an interlayer between the two faying surfaces. The microstructural development and interfacial growth of intermetallic compounds at the interface layer between Fe A36 and AA5083 after the diffusion bonding process were investigated. The joining was performed by clamping the two materials with a Ga interlayer and then heated in a furnace. The interlayer developed from this diffusion heating in air condition provides an average thickness of $30 \mu \mathrm{m}$. Characterization of intermetallic compounds was conducted using SEM-EDX and XRD. The results showed that SEM-EDX confirmed the occurrence of interdiffusion of elements from Fe A36 and AA5083 present at interlayer. XRD analysis reveals the formation of $\mathrm{Fe}_{3} \mathrm{Al}$ at the diffusion layer.
\end{abstract}

Keywords: Al-Fe; diffusion bonding; interface; interlayer diffusion; mechanical properties

\section{Introduction}

There is an increasing trend in the manufacturing industry such as light-weighting that calls for enhanced performance and functionality, which has prompted the use of hybrid and multi-material structures, hence increasing the need for joining of dissimilar materials. Solid-state diffusion bonding is a process by which two nominally flat interfaces can be joined at an elevated temperature (about 50-90\% of the absolute melting point of the parent material) using an applied pressure for a time ranging from a few minutes to a few hours. The need for solving a substantial technological and engineering challenge in the joining of dissimilar materials [1] is essential in complex-function industrial applications [2,3]. The reduction in car body weight is attainable from the combination of steel with aluminum in car body modularisation construction which results in less fuel consumption [2]. Until today, mechanical assembly methods used to join dissimilar metals are riveting, screwing, clinching, or roll bonding [4-6]. This research focuses on the integration of two dissimilar metals, also known as the Joining of Dissimilar Metal (JDM). JDM can leverage the advantageous properties of two different materials in a single component. JDM has been studied widely due to several unresolved issues related to chemical incompatibilities that lead to the formation of brittle intermetallic phases and the weakness of joining due to differences in the thermophysical properties of the materials [7].

In recent years, new welding technologies, such as explosive welding and friction welding, have been successfully used without going from solid to a liquid state. Welding dissimilar materials such as aluminum to steel are difficult due to variations in infusion temperatures, thermal conductivity, 
and mutual solubility [8]. These downsides can be overcome mainly through the introduction of strong bonding methods, such as friction welding, fusion welding and diffusion bonding [7].

There is an essential need to control the rising prevalence of an intermetallic compound (IMC) layer in the welding of steel to aluminium and its alloys. Recent studies on the combination of materials have demonstrated that the use of a cover plate over the aluminium surface for heat transmission is useful to avoid high transition metal costs.

Fusion welding is used to combine steel (stainless steel, SS) with other metal (i.e., titanium, Ti) due to the uncontrolled IMC formed in the welded zone. Excessive heat and a large amount of component mixing significantly lower the strength of the welded joints. The weld is not greatly embrittled by IMC and its thickness remains low. A thin IMC layer is difficult or impossible to obtain through JDM by conventional welding processes due to low cooling rates and high heat inputs in fusion welding processes, instead they accelerate the intermetallic growth rates [9]. Mudali et al. [10] reported that friction welding causes poor corrosion resistance and bendability in SS-Ti joints. While explosion welding has been used in many applications to clad Ti to SS plates, however, the safe use of Ti-SS joints is questionable due to high residual stresses ( 1000 MPa) and the formation of brittle IMC such as FeTi and $\mathrm{Fe}_{2} \mathrm{Ti}[11]$.

Solid-state diffusion bonding is known as a solution to produce material joints with favorable properties that could address the aforementioned problems. Nonetheless, it should be noted that direct joining results in the formation of different IMCs that are brittle and affect the strength of joining. Ghosh and Chatterjee [12] reported the formation of $\sigma$-phases, $\mathrm{FeTi}_{1} \mathrm{Fe}_{2} \mathrm{Ti}_{4} \mathrm{O}, \mathrm{Fe}_{2} \mathrm{Ti}, \mathrm{NiTi}, \mathrm{NiTi}_{2}$, and $\mathrm{Cr}_{2} \mathrm{Ti}$ in the commercially pure $\mathrm{Ti} \mathrm{Ti}(\mathrm{CP}-\mathrm{Ti})$ and SS4 reaction region that were bonded at a temperature range between 800 and $950^{\circ} \mathrm{C}$. They also concluded that the presence of these IMCs contributes to a reduction in tensile strength up to $76 \%$ (242 MPa) in comparison to the parent metal. Meanwhile, the diffusion bonding between aluminium to steel was reported to produce brittle formations of IMC phases such as $\mathrm{FeAl}_{3}, \mathrm{Fe}_{2} \mathrm{Al}_{5}, \mathrm{FeAl}_{2}$ and $\mathrm{FeAl}$ due to the near-to-zero solubility of iron in aluminum [8].

Successful diffusion bonding is seldom fulfilled in the joining of aluminum alloys in the air due to the presence of a native oxide layer on the surface. The oxide layer impedes interdiffusion by acting across the bonding surfaces as a diffusion barrier. Thus, making the oxide layer very stable and has limited solubility even at high temperatures in the parent metal [13]. The problem can be overcome by a combination of bonding surface preparation or/and adding surface interlayers to improve the conventional diffusion bonding processes.

Fitzpatrick et al. [14] investigated the joining of aero components through diffusion and claimed that joining surfaces by any solid-state methods needs to be as smooth as possible to allow good contact. Chemical machining techniques with a standard surface roughness (Ra) of 0.8 to $1.0 \mu \mathrm{m}$ have been developed to provide the necessary smooth surface roughness finish required for diffusion bonding. On the other hand, after the faying surface was given a surface treatment before proceeding with bonding, Shirzadi and Wallach have used one such treatment effectively to combine superalloys and aluminum alloys $[15,16]$. The method removes or modifies a continuous oxide film on the surface, and its reformation is prevented by laminating a very thin layer of gallium (Ga) on the mating surface, thus isolating it from the environment.

The objective of this work is to investigate the surface microstructure and distribution phase for the gallium-assisted diffusion bonding process at the joining between marine grade alloy AA5083 and Fe A36, where the characterization was conducted using SEM-EDX and XRD.

\section{Experimental Procedures}

\subsection{Materials}

In this work, AA5083 was selected based on its suitability and properties in marine atmospheres. Together with magnesium, manganese is used as a major element in alloying the 5xxx series to transform their physical property from a moderate to a high strength alloy. Solid gallium, which is 
blue-gray metal with an orthorhombic crystalline structure, was used. Solid gallium is soft enough to be cut with a knife. It is stable in air and water, but it reacts with and dissolves in acids and alkalis. Chemical properties of gallium used are with a density of 5.1 g.cm ${ }^{-3}$ at $20^{\circ} \mathrm{C}$, a melting point of $29.8^{\circ} \mathrm{C}$, and a boiling point of $2204{ }^{\circ} \mathrm{C}$

Fe A36 is a series of low carbon steel and a general range of mild steel is $0.05 \%$ to $0.35 \%$ Carbon. Mild steel, also known as low carbon steel, is the main iron component throughout the process of heat treatment, as it contains several desirable characteristics. Mild steel is very versatile, low cost and has good mechanical properties. Parts, bolts and nuts are also made of mild steel (up to $0.25 \%$ C), due to its toughness and ductility characteristics [17]. The chemical compositions of the raw materials are shown in Table 1.

Table 1. Chemical Composition specification (wt. \%) of Raw Materials.

\begin{tabular}{ccccccccc}
\hline & Al & Mg & Mn & Zn & Cr & Si & Fe & C \\
\hline AA5083 & 92 & 4.9 & 0.4 & 0.2 & 0.2 & 0.4 & - & - \\
Fe A36 & - & - & 1.03 & - & - & 0.28 & 98 & 0.29 \\
\hline
\end{tabular}

\subsection{Sample Fabrication}

The base metals AA5083 aluminium alloy and Fe A36 used in this investigation were bar-shaped specimens (10 mm length, $10 \mathrm{~mm}$ width, and $50 \mathrm{~mm}$ height). The base metal alloys surfaces were first polished with 1200 grade emery paper to prepare the surface and remove oxide layer. Then, the metal alloys surfaces were coated with Ga before holding Al-Fe specimens using a clamp or fixture. The pressure applied in the diffusion bonding process was $3 \mathrm{MPa}$ [18]. The inner side of the clamp surfaces that was used for holding the parent metals together was smeared with boron nitride to avoid specimens from sticking to the clamp during the heating process. The joint metal alloys were put into the furnace at a $550{ }^{\circ} \mathrm{C}$ bonding temperature for 60-min dwelling time. The assembly of metal alloys is shown in Figure 1.

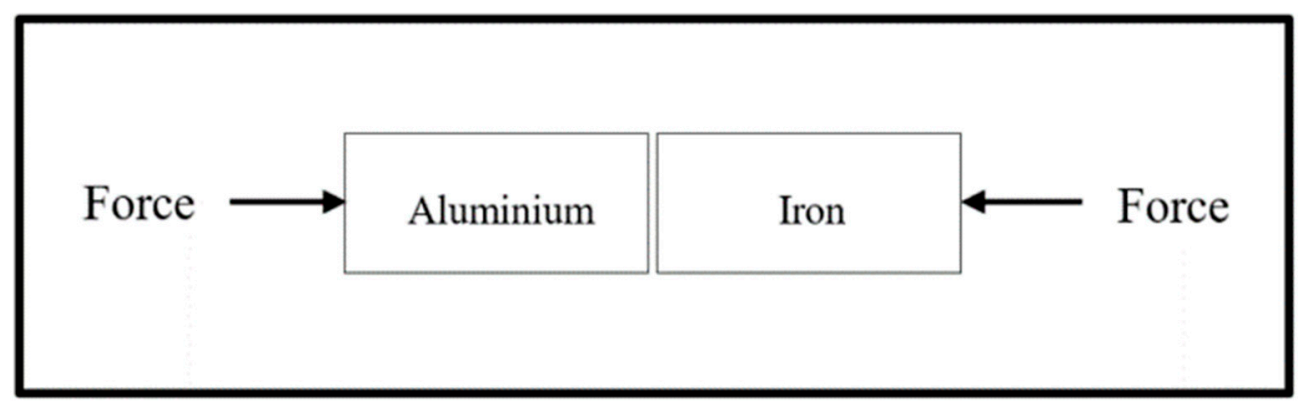

Figure 1. Diagram of Specimens Assembly.

\subsection{Surface Roughness Analysis}

The faying surface roughness ( $\mathrm{Ra}$ ) of 0.8 to $1.0 \mu \mathrm{m}$ was achieved to remove the oxide film, which facilitated great surface contact for the optimum diffusion bonding process [14]. Prior to heating the specimen in the furnace, the samples were polished using emery papers. The value of surface roughness of the polished raw materials was observed using the Surface Roughness Tester machine. The surface that was polished with 1200 emery paper grade size produced the smallest roughness values of $0.557 \mu \mathrm{m}$ and $1.223 \mu \mathrm{m}$ for aluminium and steel, respectively, as compared to using the 400 or 800 grade.

\subsection{Experiments}

The diffusion of aluminium and steel was analyzed to observe the structure composition on both parent metals at the interfacial zone using a Scanning Electron Microscope (SEM) with Energy-Dispersive 
X-ray Spectroscopy (EDX), while the distribution phase was analyzed using X-Ray Diffraction (XRD), and the strength of the joint was observed using an Izod Impact Test. The development of an interlayer with a 30- $\mu \mathrm{m}$ thickness was viable when the specimens were heated in air for $60 \mathrm{~min}$.

\section{Results and Discussion}

\subsection{X-ray Diffraction (XRD)}

The existence of phases in the IMC was detected at the surfaces of the broken joints, as shown by the XRD pattern in Figure 2. IMCs of $\mathrm{Al}_{8} \mathrm{Fe}_{5}$ and $\mathrm{AlFe}_{3}$ on the steel and aluminium, respectively, occurred to form the main elements that enabled the joining process. $\mathrm{AlMg}$ and $\mathrm{Fe}_{7} \mathrm{C}_{3}$ were detected on the as-received aluminium and steel raw materials, respectively.

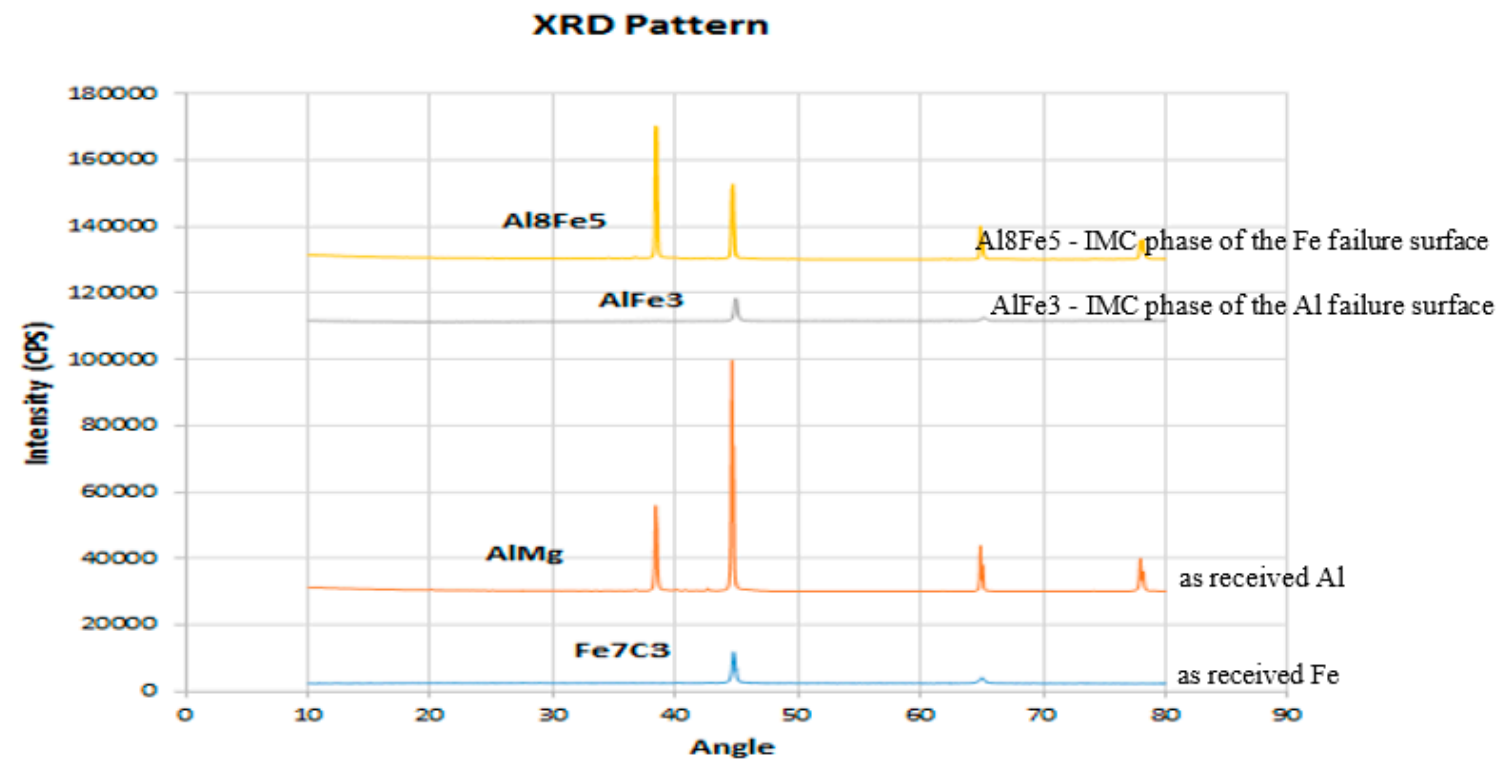

Figure 2. XRD Pattern Analysis of as-received Samples Fe A36, Al 5083, Al and Fe.

Atomic diffusion influences the formation of the diffusion layer via the diffusion of elements from both sides, rapidly, once the holding temperature is expanded to the necessary level. The ideal chemical joint between the two metals is great if the inter-diffusion occurs without any development of voids and IMC phases. These outcomes are in concurrence with Fick's Second Law, a fractional differential equation that portrays the rates at which atoms are diffused and redistributed in materials. The mechanical properties were influenced by parameters of condition arrangement and composition of phases during the welding process. The IMC develops consistently at a suitable temperature on the bonding area of the joints [17]. The composition of $\mathrm{Fe}_{\mathrm{x}} \mathrm{Al}_{\mathrm{y}}$ phases is obtained as an intermetallic compound at the Al-Fe interlayer due to the diffusion within the material interface.

The molecule distribution of intermetallic compounds does not have a destructive impact on the joint properties, instead, they reinforce the joints. They also do not affect the plasticity of the joint. When metals are connected and the thickness of intermetallic compounds develop past $5 \mu \mathrm{m}$, the plasticity and quality of joints are reduced. At a high temperature, $\mathrm{Al}$ atoms diffuse a lot faster than those of $\mathrm{Fe}$, due to the potential activation energy consumed by aluminium. The Fe atoms also diffuse over the interface into the aluminum side to form cavities in agreement with the Kirkendall effect. Cavities at the interface reduce the interface bonding quality at the joint if specimens are heated to over the most extreme temperature-nearly to the melting temperature.

The thickness of the intermetallic compound rises proportionally to the holding time. With the least holding time, the diffusion layer thickness is minimum because fewer atoms are allowed to diffuse into one another. The increase in holding time to a maximum level increases grain boundary vibration 
which allows more atoms to diffuse to create intermetallic layers, which in turn increases the diffusion layer thickness.

\subsection{Scanning Electron Microscope (SEM)-EDX Analysis}

Results from SEM showed that the composition of $\mathrm{Al}$ is higher than $\mathrm{Fe}$ in the interlayer. Gallium was also present as a decomposition in the interlayer critical zone. The broken line of the failure surface is located closer to the aluminium parent metal.

An analysis by EDX for the composition of the interlayer at the cross-section on the aluminium and steel surfaces of the broken Al-Fe joint is shown in Figure 3. In Figure 3a, the weight of aluminium is 46.6 per cent, nearly half of the whole weight composition. Gallium contributes to $32.4 \%$ of weight percentage, at which, more than one-third of the gallium interlayer appears on surface of the broken aluminium specimen. In Figure $3 b$, it is observed that the amount of aluminium is $11.3 \%$ of the weight percentage. The amount of gallium interlayer found on the surface of the broken steel specimen is $36.6 \%$ of the weight percentage, almost similar to the amount found on the broken surface of aluminium. This indicates that gallium does not have much influence on the strength of bonding, because the amount of gallium interlayer is equal on both sides of the broken surfaces. The amount of iron is dominant at $1.2 \%$ on the steel, as compared to $0.2 \%$ on the aluminium specimen.

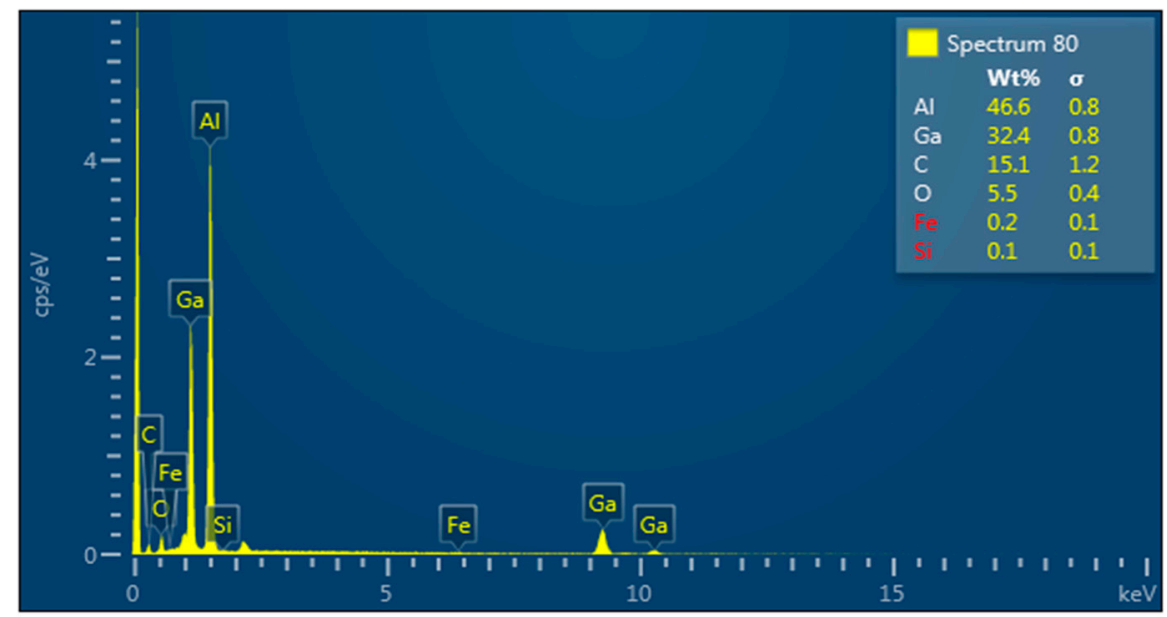

(a)

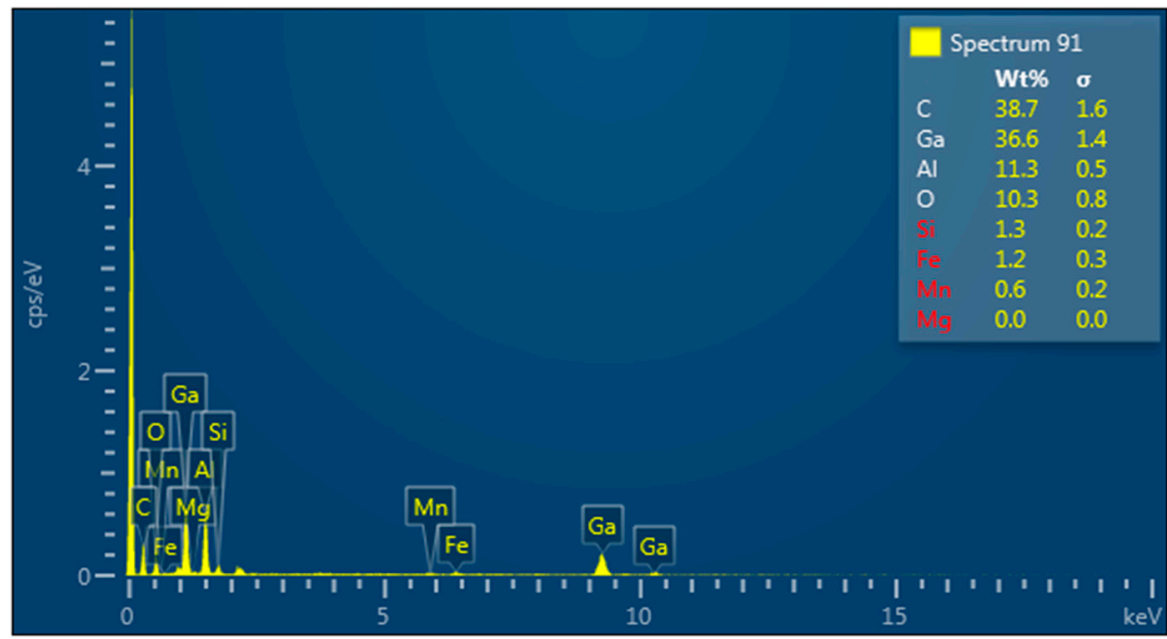

(b)

Figure 3. (a) Composition of elements on aluminium specimen for Al-Fe-by EDX. (b) Composition of elements on steel specimen for Al-Fe-by EDX. 
Figure 4 shows the percentage of aluminium and iron content at the interface of the Al-Fe joint. In the diagram, the two main graphs (i.e., Fe and Al), represent the dominant elements of composition. The red graph represents iron content, while the green represents aluminium content. On the left-hand side of the bonding line, the red Fe graph magnifies the average value of about $200 \mathrm{cps}$. Once the Fe graph crosses the bonding line, it starts to move downwards approaching 0 cps as it travels to the right into/towards the end of the aluminium specimen. This means the content of iron is decreasing as it is moves away from the bonding line towards the righthand direction. In contrast, the green $\mathrm{Al}$ graph highlights the decrease in the average value from about $250 \mathrm{cps}$ within a range of $300 \mu \mathrm{m}$ from the bonding line (on the righthand/aluminium side of the line) to the value of nearly 0 cps as it travels to the left into/towards the end of the steel specimen.

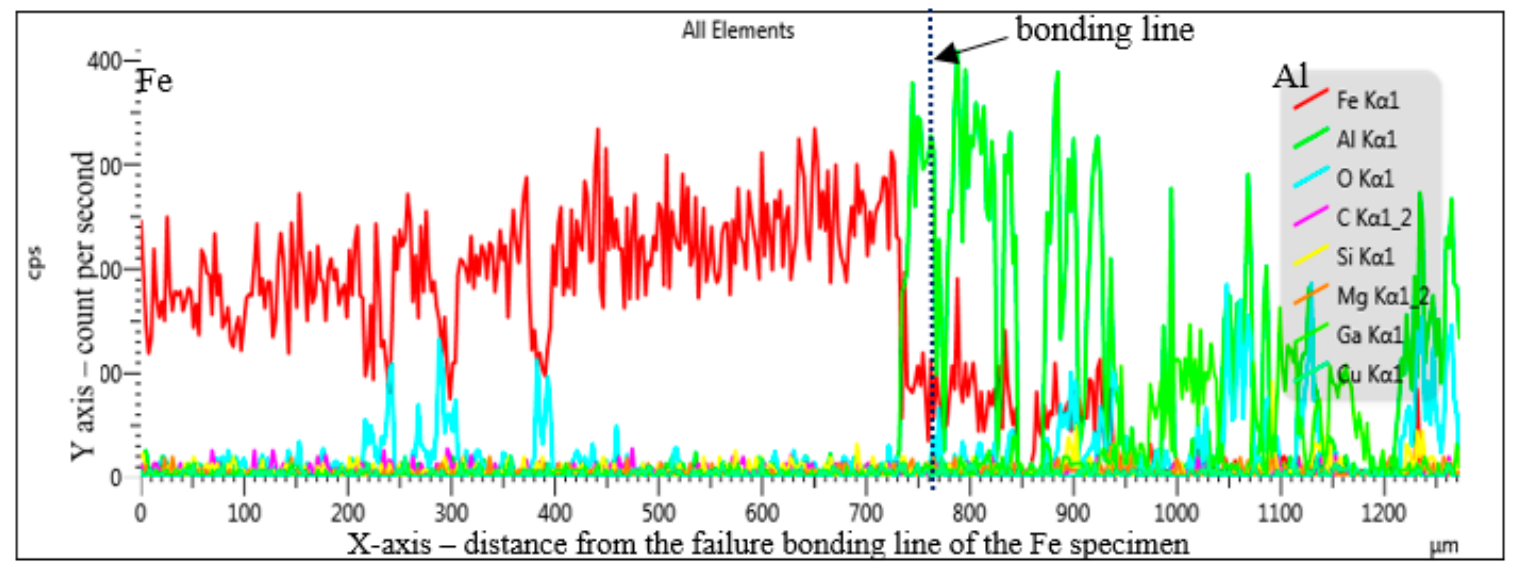

Figure 4. Linescan Analysis along the bonding line of Al-Fe Joint Cross Section.

Topographies for the joint of Fe A36 and Al 5083 at various magnification scales are shown in Figure 5. Figure 5a shows the topography of $\mathrm{Fe}$ and $\mathrm{Al}$ at the 72-magnification scale. The diffusion-affected IMC boundary layer is clearly seen even at a small intensification level. There was a diffusion process that took place due to the reaction of gallium on the specimen's faying surfaces.

There are micro voids and holes in between the gap for this Al-Fe joint due to the insufficient pressure supplied at both ends of the joining specimens. Even though it was successfully bonded, the unbonded portion was spotted on the faying surface. As seen in Figure 5b,c, there is a spot of an unsuccessful reaction developed at the mating surface even though gallium was providing a pre-interaction environment on the faying surfaces. In Figure 5d,e, there is another gap, and the void appears at the mating surface.

It was possible for the specimens to be joined; however, the brittle IMCs to be specific, the $\mathrm{AlFe}_{3}$ and $\mathrm{Al}_{8} \mathrm{Fe}_{5}$ phases were formed at the interface. For best conditions for the diffusion development process for any material, one must incorporate the closure of the faying surface, a growth of IMC, and the ignition of the Kirkendall voids [19]. The amount of $\mathrm{AlFe}_{3}$ and $\mathrm{Al}_{8} \mathrm{Fe}_{5}$ phases at the diffusion can be controlled by the utilization of interlayers. The usage of gallium as an interlayer promotes the formation of intermetallic phases via the coexistence of a solid solution at the joining interface, hence, the correct setting of bonding parameters is anticipated in accordance with the law of parabolic diffusion. Recently, it was found that the consequence of interlayer on the faying surfaces of the diffusion bonding helps to improve the strength of the joint as, physically, it improves the intermetallic phase brittleness, and, chemically, it promotes the process of atoms migration between aluminium and mild steel. 

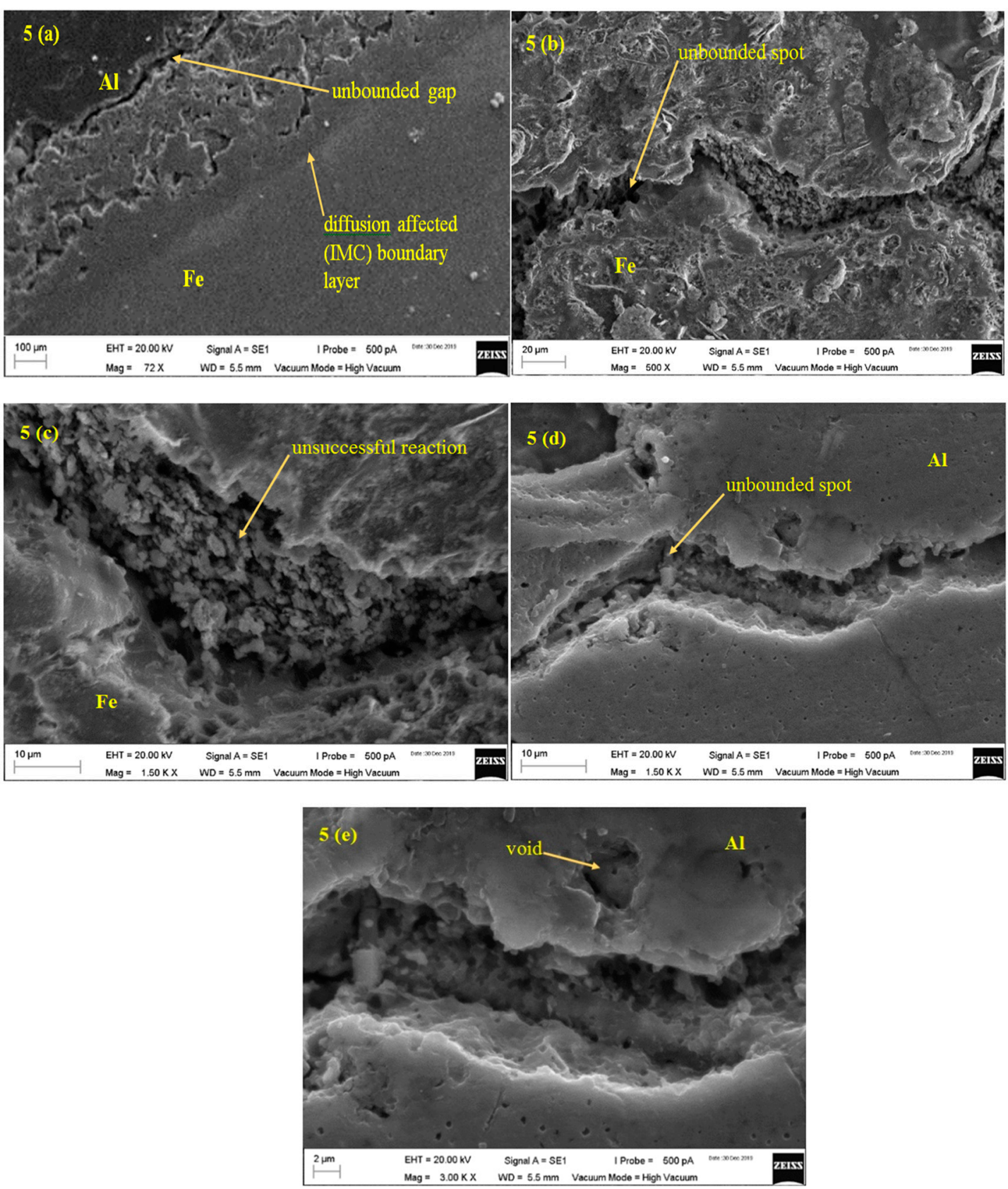

Figure 5. Topography of specimens; Figure 5(a) Topography of Al-Fe joint at 72 magnification Cross Section by SEM; Figure 5(b): Topography of Al-Fe joint at 500 magnification Cross Section by SEM; Figure 5(c): Topography of Al-Fe joint at 1500 magnification Cross Section by SEM; Figure 5(d): Topography of Al-Fe joint at 1500 magnification Cross Section by SEM; Figure 5(e): Topography of Al-Fe joint at 3000 magnification Cross Section by SEM.

\section{Conclusions}

- In this work, $\mathrm{Al}_{8} \mathrm{Fe}_{5}$ and $\mathrm{AlFe}_{3}$ were joined using a diffusion bonding method. The results showed that the bonding interaction was exhibited by the diffusion-affected IMC boundary layer through the existence, enhancement and reaction of gallium found as an interlayer between these two metals.

- The detection of $\mathrm{Al}_{8} \mathrm{Fe}_{5}$ and $\mathrm{AlFe}_{3}$ on the broken surfaces of $\mathrm{Al}-\mathrm{Fe}$ joints showed the presence of an intermetallic compound phase. Meanwhile, the appearance of microvoids and holes between 
the gap of Al-Fe joint is due to the insufficient pressure supplied at both ends of the joining specimen assembly, which needs to be improved in the future.

- These gaps and voids showed an unbounded portion, despite the fact that the metals were physically bonded, due to an unsuccessful reaction, even though, presumably, the gallium may provide a pre-interaction condition of the faying surfaces.

- It has been proven that gallium does not influence the strength of the bonding, as the amount of the gallium interlayer is equally present on both sides of the broken surfaces.

- The result obtained is very practical for use in marine research applications in the future, and as a mitigation factor to strengthen structures. The future research work will be conducted to enhance the current study by infusing additional mechanical tests, such as tensile or shear tests.

Author Contributions: Conceptualization, A.I., W.B. and P.B.H.; methodology, A.I., and W.B.; software, W.B.; validation, P.B.H. and A.M.S.; formal analysis, N.B.S.; investigation, A.I. and W.B.; resources, A.I.; data curation, W.B.; writing — original draft preparation, A.I.; writing—review and editing, N.B.S.; visualization, A.I.; supervision, P.B.H. and A.M.S.; project administration, P.B.H.; funding acquisition, P.B.H. All authors have read and agreed to the published version of the manuscript.

Funding: This research was funded by FRGS, grant number 015MAO-076.

Acknowledgments: The authors would like to acknowledge the grant support by FRGS 015MAO-076 in performing this research work.

Conflicts of Interest: The authors declare no conflict of interest.

\section{References}

1. Katayama, S. Laser welding of aluminium alloys and dissimilar metals. Weld. Int. 2004, 18, 618-625. [CrossRef]

2. Sierra, G.; Wattrisse, B.; Bordreuil, C. Structural analysis of steel to aluminum welded overlap joint by digital image correlation. Exp. Mech. 2008, 48, 213-223. [CrossRef]

3. Eelman, D.; Dahn, J.; MacKay, G.; Dunlap, R. An investigation of mechanically alloyed Fe-Al. J. Alloys Compd. 1998, 266, 234-240. [CrossRef]

4. Lee, W.-B.; Schmuecker, M.; Mercardo, U.A.; Biallas, G.; Jung, S.-B. Interfacial reaction in steel-aluminum joints made by friction stir welding. Scripta Materialia 2006, 55, 355-358. [CrossRef]

5. Brockmann, R.; Dickmann, K.; Radscheit, C.; Schubert, E.; Sepold, G. Method for the laser beam joining of aluminum and steel in the thin sheet range. J. Weld. Cutt. 1996, 3, 46-47.

6. Nezhad, M.S.A.; Ardakani, A.H. A study of joint quality of aluminum and low carbon steel strips by warm rolling. Mater. Des. 2009, 30, 1103-1109. [CrossRef]

7. Shirzadi, A.A.; Laik, A.; Tewari, R.; Orsborn, J.; Dey, G.K. Gallium-assisted diffusion bonding of stainless steel to titanium; microstructural evolution and bond strength. Materialia 2018, 4, 115-126. [CrossRef]

8. Torkamany, M.; Tahamtan, S.; Sabbaghzadeh, J. Dissimilar welding of carbon steel to 5754 aluminum alloy by Nd: YAG pulsed laser. Mater. Des. 2010, 31, 458-465. [CrossRef]

9. Campbell, F.C. Joining: Understanding the Basics; ASM International: ASM World Headquarters, Materials Park, $\mathrm{OH}, \mathrm{USA}, 2011$.

10. Kamachi Mudali, U.; Ananda Rao, B.; Shanmugam, K.; Natarajan, R.; Raj, B. Corrosion and microstructural aspects of dissimilar joints of titanium and type 304L stainless steel. J. Nucl. Mater. 2003, 321, 40-48. [CrossRef]

11. Kahraman, N.; Gülenç, B.; Findik, F. Joining of titanium/stainless steel by explosive welding and effect on interface. J. Mater. Process. Technol. 2005, 169, 127-133. [CrossRef]

12. Ghosh, M.; Chatterjee, S. Diffusion bonded transition joints of titanium to stainless steel with improved properties. Mater. Sci. Eng. A 2003, 358, 152-158. [CrossRef]

13. Lavernia, E.J.; Grant, N.J. Aluminium-lithium alloys. J. Mater. Sci. 1987, 22, 1521-1529. [CrossRef]

14. Fitzpatrick, G.; Broughton, T. Diffusion bonding aeroengine components. Def. Sci. J. 1988, 38, 477-485. [CrossRef]

15. Shirzadi, A.; Wallach, E. New method to diffusion bond superalloys. Sci. Technol. Weld. Join. 2004, 9, 37-40. [CrossRef] 
16. Ghoshouni, A.A.S.; Wallach, E.R. Surface Treatment of Oxidizing Materials; Google Patents: Washington, DC, USA, 2003.

17. Schneider, J.; Radzilowski, R. Welding of very dissimilar materials (Fe-Al). JOM 2014, 66, $2123-2129$. [CrossRef]

18. Kazakov, N.F. Diffusion Bonding of Materials; Elsevier: New York, NY, USA, 2013.

19. Mo, D.-F.; Song, T.-F.; Fang, Y.-J.; Jiang, X.-S.; Luo, C.Q.; Simpson, M.D.; Luo, Z.-P. A review on diffusion bonding between titanium alloys and stainless steels. Adv. Mater. Sci. Eng. 2018, 2018, 8701890. [CrossRef]

(C) 2020 by the authors. Licensee MDPI, Basel, Switzerland. This article is an open access article distributed under the terms and conditions of the Creative Commons Attribution (CC BY) license (http://creativecommons.org/licenses/by/4.0/). 